\title{
Comparison of Cardiovascular Risk Factors among Somalis Living in Norway and Somaliland
}

\author{
Soheir H. Ahmed ${ }^{1,2,+, *}$, Niki Marjerrison ${ }^{1,+}$, Marte Karoline Råberg Kjøllesdal ${ }^{1,3}$, Hein Stigum ${ }^{1}$, \\ Aung Soe Htet ${ }^{1,4}$, Espen Bjertness ${ }^{1}{ }^{\mathbb{D}}$, Haakon E. Meyer ${ }^{1,5}$ and Ahmed A. Madar ${ }^{1}$ \\ 1 Department of Community Medicine and Global Health, Institute of Health and Society, University of Oslo, \\ 0318 Oslo, Norway \\ 2 College of Medicine \& Health Science, University of Hargeisa, 002563 Hargeisa, Somaliland \\ 3 Health Services Research, Norwegian Institute of Public Health, 0213 Oslo, Norway \\ 4 International Relations Division, Ministry of Health and Sports, Nay Pyi, Taw 15011, Myanmar \\ 5 Division of Mental and Physical Health, Norwegian Institute of Public Health, 0473 Oslo, Norway \\ * Correspondence: asliahmed@live.com; Tel.: +47-22-850-634; Fax: +47-22-850-590 \\ + These authors contributed equally to this work.
}

Received: 5 June 2019; Accepted: 28 June 2019; Published: 3 July 2019

\begin{abstract}
Objective: We aimed to assess and compare cardiovascular disease (CVD) risk factors and predict the future risk of CVD among Somalis living in Norway and Somaliland. Method: We included participants (20-69 years) from two cross-sectional studies among Somalis living in Oslo $(n=212)$ and Hargeisa $(n=1098)$. Demographic data, history of CVD, smoking, alcohol consumption, anthropometric measures, blood pressure, fasting serum glucose, and lipid profiles were collected. The predicted 10-year risk of CVD was calculated using Framingham risk score models. Results: In women, systolic and diastolic blood pressure were significantly higher in Hargeisa compared to Oslo $(p<0.001)$, whereas no significant differences were seen in men. The ratio of total cholesterol to high-density lipoprotein (HDL) cholesterol was significantly higher in Hargeisa compared to Oslo among both men ( 4.4 versus $3.9, p=0.001$ ) and women ( 4.1 versus $3.3, p<0.001)$. Compared to women, men had higher Framingham risk scores, but there were no significant differences in Framingham risk scores between Somalis in Oslo and Hargeisa. Conclusion: In spite of the high body mass index (BMI) in Oslo, most CVD risk factors were higher among Somali women living in Hargeisa compared to those in Oslo, with similar patterns suggested in men. However, the predicted CVD risks based on Framingham models were not different between the locations.
\end{abstract}

Keywords: Somalis; comparison; cardiovascular disease risk factors; Framingham risk score

\section{Introduction}

Cardiovascular diseases (CVDs) remain the leading cause of death worldwide and pose a steadily increasing burden throughout low- and middle-income countries, including throughout sub-Saharan Africa [1-3]. The majority of CVD is caused by the presence and complex interaction of various modifiable risk factors, including hypertension, diabetes, dyslipidaemia, overweight and obesity, tobacco smoking, unhealthy diet, and harmful use of alcohol [4].

In sub-Saharan Africa, economic development has been linked to globalization and urbanization, which have been identified as root causes of a nutrition transition and the increasing prevalence of CVDs and their risk factors [5]. Somaliland is a region in the Horn of Africa with a population of approximately 4.5 million people that is currently undergoing such urbanization and epidemiological transitions $[3,6]$. However, we are not so far aware of any study reporting on the prevalence of CVD and its associated risk factors in Somaliland [7]. 
The ongoing conflict in the Horn of Africa has also led to a large diaspora of Somalis around the world [8]. Many Somalis have migrated to Norway, where they make up one of the largest immigrant groups from a non-Western country [9]. Previous studies on immigrants in Norway have had heterogeneous results regarding CVD risk factors [10-12]. However, despite the concentration of Somalis in Norway and the suggestions of increased CVD risk among ethnic minority groups, little research has been conducted on CVD risk factors among Somalis living in Norway [13].

Models such as the Framingham risk score have been developed in an effort to use data that can be easily collected to assess the combined effect of various risk factors on the risk of experiencing future CVD events [14,15]. However, the Framingham risk score has been criticized for both overestimating $[16,17]$ and underestimating the absolute risk in different socioeconomic groups [18] and populations. Nonetheless, the Framingham risk score has been validated for use in various populations, including those of African origin living in the United States [14,19], and it also remains a valuable tool for disease projection estimates where there are only limited cross-sectional data available [20].

Unfortunately, the scarce data specific to Somalis limit the means and incentive for effective and increasingly necessary CVD prevention, intervention, and treatment $[1,21]$. We have previously reported high body mass index (BMI) and high prevalence of overweight and obesity among Somali men and women in Oslo compared to their counterparts in Hargeisa [22]. The aim of the current analysis is to assess and compare CVD risk factors and predict future CVD risk among Somalis living in Hargeisa, Somaliland and in Oslo, Norway.

\section{Materials and Methods}

In the present comparative study, we included data from two cross-sectional studies among Somalis living in Norway (Oslo study) and Somaliland (Hargeisa study), conducted between December 2015 and October 2016 and between March and September 2016, respectively. In both studies, participants were excluded if they were confirmed pregnant or if they were suffering from kidney or liver failure or cancer.

\subsection{Oslo Study}

The Oslo study was conducted in the Sagene district, which was selected because it has one of the highest populations and concentrations of people of Somali origin living there-approximately 1200 persons in total [9]. We established cooperation with user partners such as Somali organizations, a healthy life center, a volunteer center, the district medical officer, the community development center, and the local Somali radio station to share information about the study. We attempted to contact every adult person of Somali origin living in the district, and those available were invited to participate in the study. A total of 271 eligible men and women aged 20-69 years were invited, resulting in a final sample of 111 women and 110 men. Fifty persons who were contacted either did not want to participate or did not come for the appointment.

\subsection{Somaliland Study}

Due to the lack of data on the prevalence of risk factors in the population under study, the sample size was calculated using the diabetes prevalence of $4 \%$ [23]. There is no population registry in Somaliland, and the only available registry is the number of households. Each household has a unique number. Hargeisa city comprises five major districts which are each further subdivided into four main subdistricts. The sample design was two-stage cluster sampling, and the twenty subdistricts were targeted as the primary sampling units (PSUs). Ten subdistricts were randomly selected from the twenty PSUs (first stage), and a total of 1100 households were randomly selected from them (second stage) based on the probability proportionate to size (PPS) in each subdistrict.

In each selected household, all eligible persons aged 20-69 years living in the house were listed on a Kish household coversheet [24]. Men and women were listed in order of decreasing age and 
given a rank number. If the selected person rejected participation or was not present at home after two attempts, the next person on the Kish list was selected until there was one person from each household participating in the study. If there was nobody at home on the day of the study, a notification card was left at the door, and we returned the next day until we had one participant from each house. Data collection continued until there were 1100 participants, resulting in a final sample of 955 women and 145 men.

\subsection{Data Collection}

The two studies followed similar data collection methods and used the same tools. The Hargeisa study followed the World Health Organization (WHO) STEPwise approach [25]. Interviewer-administered questionnaires were used to collect information on years of education, occupation, marital status, personal medical history, medication use, smoking habits, and alcohol consumption. Participants were asked if they consume alcohol such as beer, wine, spirits, or other alcohol types (yes/no). They were also asked about the type of oil used for food preparation (such as cooking, frying, and baking).

In both studies, weight and height were measured with participants standing without shoes and wearing light clothing. Body weight (kilograms) was recorded to the nearest $0.1 \mathrm{~kg}$ and measured using an Omron medical scale that was checked every day with a known weight. Height (centimeters) was recorded to the nearest $0.5 \mathrm{~cm}$ and measured with a manual height-measuring instrument (SECA stadiometer) with participants standing upright with the head in the Frankfort plane. Body mass index (BMI) was calculated as weight in kilograms divided by the square of the height in meters $\left(\mathrm{kg} / \mathrm{m}^{2}\right)$.

Blood pressure $(\mathrm{mmHg})$ was measured three times at one minute intervals using a validated automatic device (Omron HBP 1300) [26] with appropriate cuffs in a sitting position after at least $5 \mathrm{~min}$ of rest. The mean of the second and third readings was used for analysis.

\subsection{Blood Sampling and Laboratory Assays}

Fasting venous blood samples were collected from participants to determine the concentrations of serum glucose and lipids (fasting serum glucose (FSG), total cholesterol (TC), high-density lipoprotein (HDL) cholesterol, low-density lipoprotein (LDL) cholesterol, and triglycerides (TG)).

In Hargeisa, samples were collected at Hargeisa Group Hospital. Blood samples were collected in serum separator gel tubes and centrifuged after $30 \mathrm{~min}$. Serum and plasma were then separated and frozen in aliquots at $-30^{\circ} \mathrm{C}$ the same day until being shipped to Oslo (Norway) where they were analyzed as one batch at the Fürst Medical Laboratory (http://www.furst.no), which has been accredited by the Norwegian Accreditation according to the standard NS-EN ISO 15189 TEST 209. The inter-assay coefficients of variation were 1.3\% (TC), 1.6\% (LDL cholesterol), 1.8\% (HDL cholesterol), and 3.8\% (TG). Total cholesterol, LDL cholesterol, HDL cholesterol, and TG were measured using an enzymatic method (ADVIA 2400 Siemens, produced by Jeol, Japan). In Oslo, blood samples were collected at the downtown office, Fürst Medical Laboratory, and were analyzed there within the same day, following the same procedure.

\subsection{Definitions of Risk Factor Variables}

Age was defined as completed years of age. Current tobacco smoking and alcohol consumption were ascertained by self-report as yes/no. Overweight was defined by a BMI of $\geq 25 \mathrm{~kg} / \mathrm{m}^{2}$ [27]. Hypertension was defined as systolic blood pressure (SBP) of $\geq 140 \mathrm{mmHg}$ and/or diastolic blood pressure (DBP) of $\geq 90 \mathrm{mmHg}$ and/or being on blood-pressure-lowering medication [7]. Diabetes was defined as fasting serum glucose (FSG) of $\geq 7.0 \mathrm{mmol} / \mathrm{L}$ and/or being on medication $[4,28]$. High cholesterol was defined as a ratio of total cholesterol (TC) to high-density lipoprotein (HDL) of $\geq 5$ and/or being on cholesterol-lowering medication [29]. 


\subsection{Statistical Analysis}

Continuous variables were expressed as means (SD), and percentages were used to express categorical variables. Significance was tested for continuous variables using independent $t$-tests and for categorical variables by chi-square test. The age-adjusted mean and prevalence were calculated by group and gender using predictive margins based on the linear and logistic regression models. To control confounding by age in the predicted means and prevalence, we fixed age at age equal to 40 years (which was closest to the mean age). Additionally, we tested for interaction between age and gender and between age and location (Hargeisa versus Oslo), assessing the marginal effect on lipid and BMI Framingham risk score models by age (Figures 1 and 2).

Data were analyzed using Stata statistical software, version 14.0 (StataCorp. College Station, TX, USA). The results were considered statistically significant with $p<0.05$.

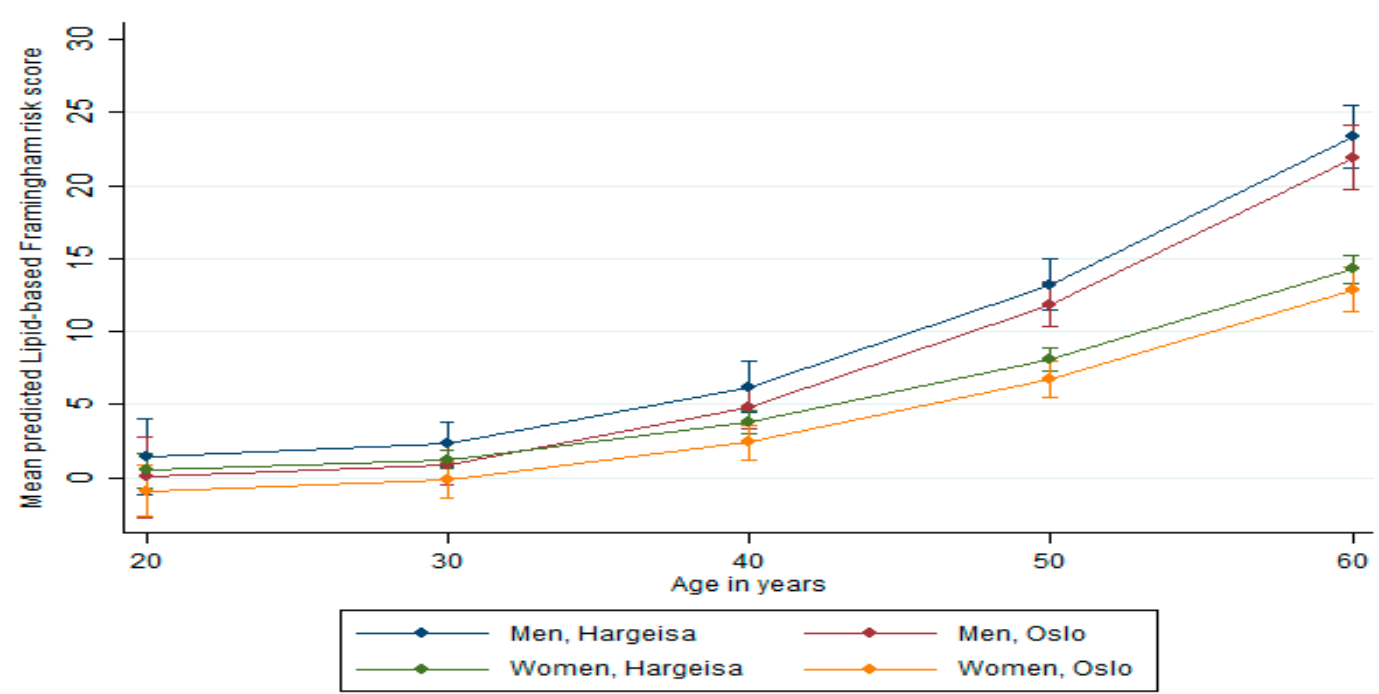

Figure 1. Lipid-based Framingham risk score by age, gender, and location (vertical lines are means with $95 \%$ confidence intervals).

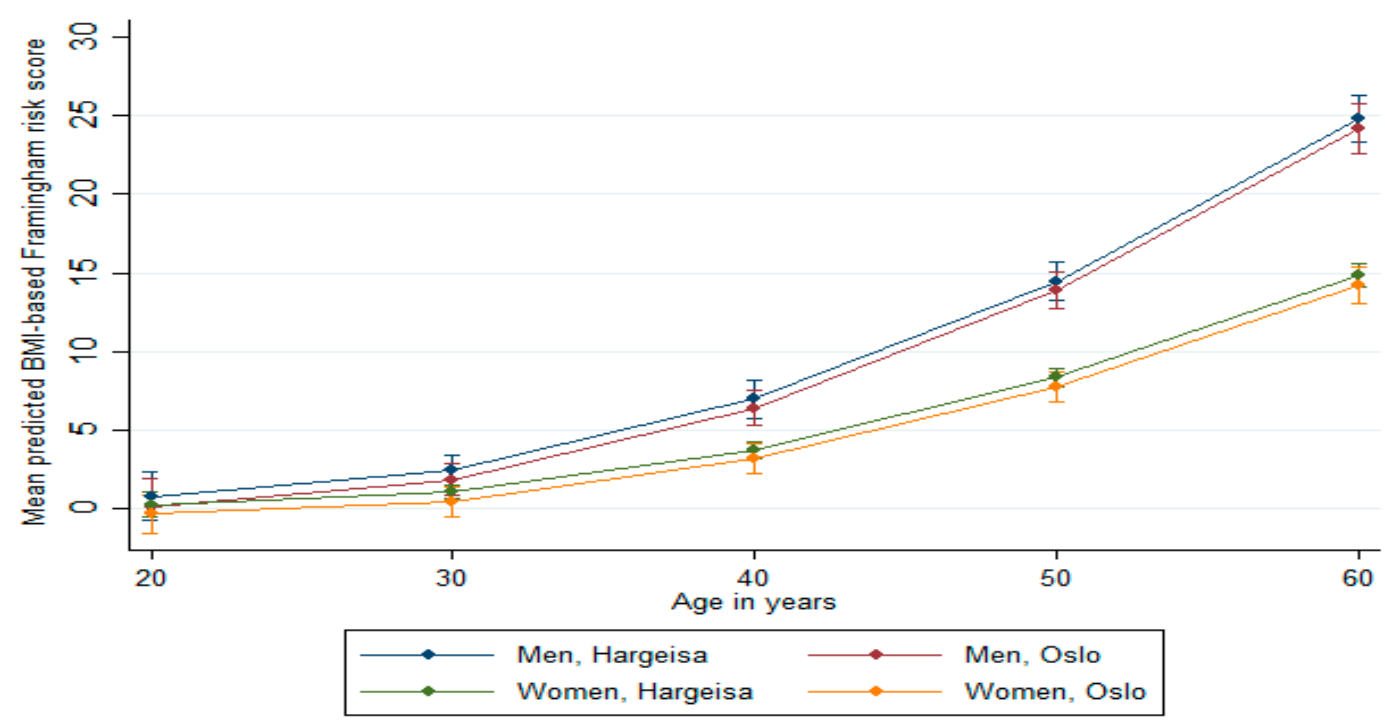

Figure 2. Body mass index (BMI)-based Framingham risk score by age, gender, and location (vertical lines are means with $95 \%$ confidence intervals). 


\subsection{Estimating the Framingham Risk Score}

The predicted 10-year risk for an incident cardiovascular event was estimated using the Framingham 10-year risk score models, as published by D'Agostino et al. in 2008 [15]. The risk score includes age, smoking status, systolic blood pressure, diabetes, total cholesterol, and HDL cholesterol [30], alternatively with BMI replacing total cholesterol and HDL cholesterol [15,30]. We used both the lipid-based and BMI-based models for the gender-specific algorithm. Individuals with prior CVD were excluded from these analyses, and only those with complete blood samples were included in the lipid-based model and analyses.

For the lipid-based equation, we included a total of 123 men (73 from Oslo and 50 from Hargeisa) and 552 women ( 82 from Oslo and 470 from Hargeisa). In the BMI-based equation, a total of 235 men (101 from Oslo and 134 from Hargeisa) and 963 women (103 from Oslo and 860 from Hargeisa) were included (Figure 3). The age-adjusted mean risk scores and percentages $(95 \% \mathrm{CI})$ of those with a predicted 10-year risk of $\geq 10 \%$ are presented. In additional analyses, Framingham risk scores were stratified by level of education.

Both studies were approved by the Regional Committee for Medical and Health Research Ethics Norway (study codes: 2015/1552 and 2015/2448 REK South-East). The Ministry of Health in Somaliland additionally approved the Somaliland study. In both studies, written informed consent was obtained from all participants.

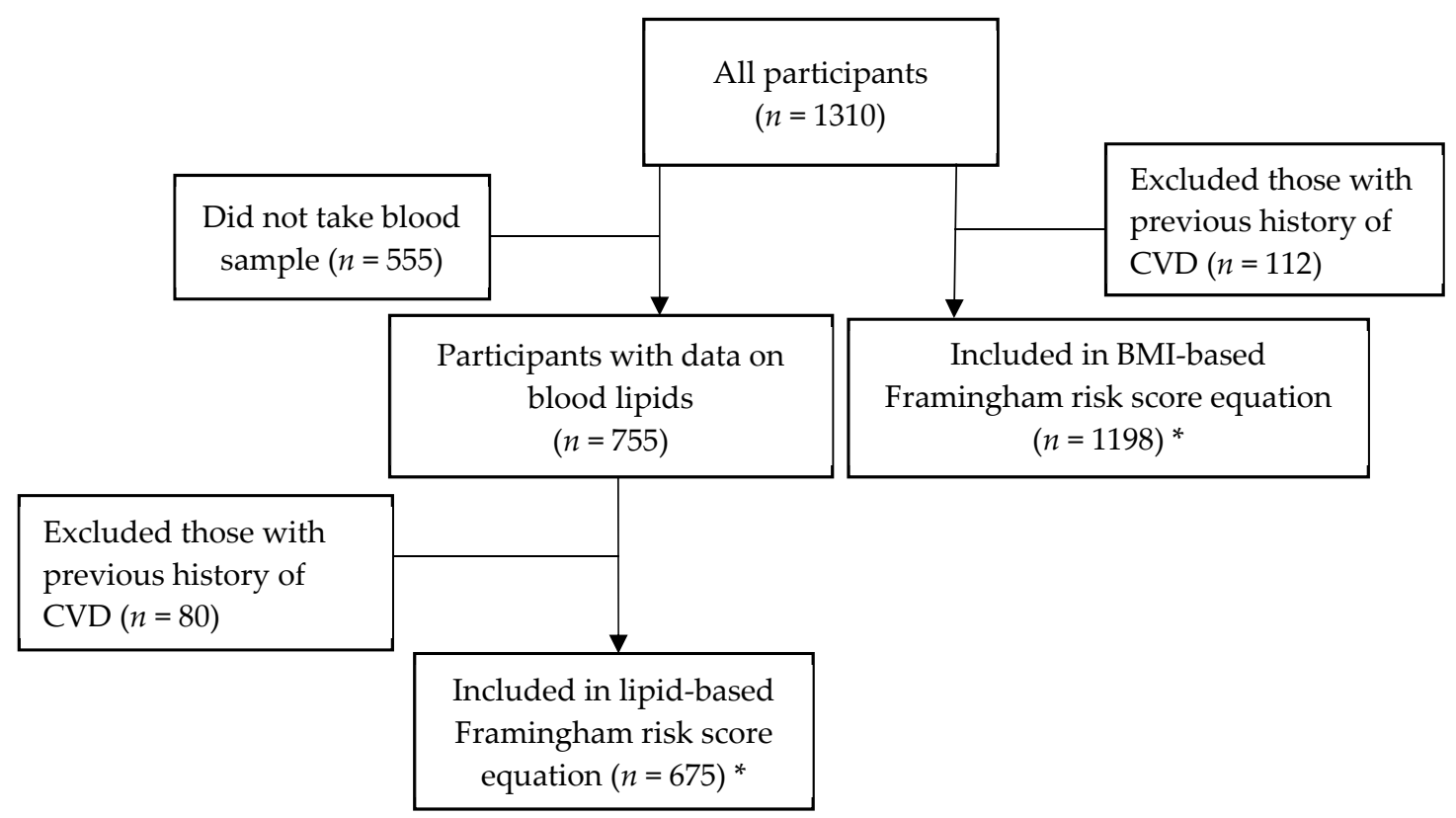

Figure 3. Flow chart illustrating participants included in the different analyses. ${ }^{*} n$ is different between those who were included in the lipid-and BMI-based Framingham risk score equations due to missing data from lab results in the lipid-based analyses.

\section{Results}

A total of 1310 participants were included in the analysis. Women from Hargeisa composed the largest subgroup with 953 participants, while 106 women participated from Oslo. Among men, there were 145 participants from Hargeisa and 106 from Oslo.

The percentage of participants with a high level of education, defined as having completed secondary school or more, was highest among men living in Oslo (89\%) and lowest among women living in Hargeisa (14\%) (Table 1). Unemployment, in turn, was lowest among men living in Oslo $(19 \%)$ and highest among women living in Hargeisa (88\%). Homemakers identifying as unemployed likely inflated this figure among women in Hargeisa. 
Table 1. Characteristics of the study population in Oslo and Hargeisa (unadjusted).

\begin{tabular}{|c|c|c|c|}
\hline Men & Oslo $(n=106)$ & Hargeisa $(n=145)$ & $p$ Value \\
\hline Age (years), Mean \pm SD & $39.4 \pm 11.0$ & $38.2 \pm 6.1$ & 0.493 \\
\hline Education $(\%) *$ & 89.4 & 52.4 & $<0.001$ \\
\hline Employment $(\%)^{* *}$ & 19.2 & 32.2 & 0.023 \\
\hline Marital status $(\%) * * *$ & 64.4 & 56.6 & 0.211 \\
\hline Body mass index, Mean \pm SD & $25.9 \pm 3.4$ & $22.1 \pm 4.6$ & $<0.001$ \\
\hline $\mathrm{SBP}(\mathrm{mmHg})$, Mean \pm SD & $126.0 \pm 17.0$ & $129.7 \pm 27.8$ & 0.185 \\
\hline $\mathrm{DBP}(\mathrm{mmHg})$, Mean \pm SD & $81.3 \pm 10.3$ & $82.7 \pm 12.7$ & 0.349 \\
\hline Women & Oslo $(n=106)$ & Hargeisa $(n=953)$ & $p$ Value \\
\hline Age (years), Mean \pm SD & $37.5 \pm 9.6$ & $39.1 \pm 14.1$ & 0.137 \\
\hline Education $(\%) *$ & 48.6 & 14.3 & $<0.001$ \\
\hline Employment $(\%)^{* *}$ & 22.3 & 88.4 & $<0.001$ \\
\hline Marital status $(\%) * * *$ & 62.9 & 78.4 & $<0.001$ \\
\hline Body mass index, Mean \pm SD & $30.0 \pm 6.7$ & $27.2 \pm 5.9$ & $<0.001$ \\
\hline $\mathrm{SBP}(\mathrm{mmHg})$, Mean \pm SD & $118.1 \pm 19.8$ & $128.2 \pm 24.6$ & $<0.001$ \\
\hline $\mathrm{DBP}(\mathrm{mmHg})$, Mean $\pm \mathrm{SD}$ & $78.3 \pm 9.7$ & $83.8 \pm 12.5$ & $<0.001$ \\
\hline
\end{tabular}

$*$ Education $=\%$ completed secondary school or more. ${ }^{* *}$ Employment $=\%$ who are unemployed. ${ }^{* * *}$ Marital status $=\%$ currently married. SBP: systolic blood pressure; DBP: diastolic blood pressure.

The mean SBP and DBP were significantly higher in women in Hargeisa than in women in Oslo $(p<0.001)$ with the same pattern suggested in men, although differences were not significant (Table 1$)$. The mean TC/HDL cholesterol ratio was significantly higher among women and men in Hargeisa when compared to men and women in Oslo (Table 2). There was no significant difference in the mean levels of FSG or TC between the two locations, but triglycerides were higher in Hargeisa (Table 2).

Table 2. Mean serum lipids (mmol/L) by location and gender adjusted for age ${ }^{\mathrm{a}}$.

\begin{tabular}{ccccccc}
\hline \multirow{2}{*}{ Variables } & \multicolumn{3}{c}{ Men } & \multicolumn{3}{c}{ Women } \\
\cline { 2 - 7 } & $\begin{array}{c}\text { Oslo } \\
(\boldsymbol{n}=\mathbf{7 6})\end{array}$ & $\begin{array}{c}\text { Hargeisa } \\
(\boldsymbol{n}=\mathbf{6 0})\end{array}$ & $\begin{array}{c}\text { Mean Difference } \mathbf{b} \\
\mathbf{( 9 5 \%} \mathbf{C I})\end{array}$ & $\begin{array}{c}\text { Oslo } \\
(\boldsymbol{n}=\mathbf{8 5})\end{array}$ & $\begin{array}{c}\text { Hargeisa } \\
(\boldsymbol{n}=5 \mathbf{5 3})\end{array}$ & $\begin{array}{c}\text { Mean Difference } \mathbf{b} \\
\mathbf{( 9 5 \%} \mathbf{C I})\end{array}$ \\
\hline $\begin{array}{c}\text { Fasting serum } \\
\text { glucose (mmol/L) }\end{array}$ & 5.3 & 5.4 & $-0.1(-0.6,0.3)$ & 5.2 & 5.4 & $-0.2(-0.6,0.3)$ \\
\hline $\begin{array}{c}\text { Triglycerides } \\
(\text { mmol/L) }\end{array}$ & 1.1 & 1.6 & $-0.5(-0.8,-0.1)$ & 0.9 & 1.3 & $-0.4(-0.5,-0.2)$ \\
\hline $\begin{array}{c}\text { Total cholesterol } \\
(\text { mmol/L) }\end{array}$ & 4.6 & 4.5 & $0.1(-0.2,0.3)$ & 4.5 & 4.7 & $-0.2(-0.3,0.02)$ \\
\hline $\begin{array}{c}\text { HDL cholesterol } \\
(\text { mmol/L) }\end{array}$ & 1.2 & 1.00 & $0.2(0.1,0.2)$ & 1.4 & 1.1 & $0.3(0.2,0.3)$ \\
\hline $\begin{array}{c}\text { LDL cholesterol } \\
(\mathrm{mmol} / \mathrm{L})\end{array}$ & 3.0 & 2.7 & $0.3(0.1,0.6)$ & 2.9 & 2.8 & $0.1(-0.1,0.3)$ \\
\hline TC/HDL ratio & 3.9 & 4.4 & $-0.5(-0.8,-0.2)$ & 3.3 & 4.1 & $-0.8(-1.0,-0.6)$ \\
\hline
\end{tabular}

${ }^{a}$ model was evaluated at age 40 years. ${ }^{b}$ (Oslo minus Hargeisa). HDL: high-density lipoprotein; LDL: low-density lipoprotein; TC: total cholesterol.

The prevalence of hypertension was significantly higher among women from Hargeisa (35\%) compared to among women from Oslo $(17 \%, p<0.001)$. In men from both Hargeisa and Oslo, the prevalence of hypertension was over $30 \%$ (Table 3 ). The prevalence of high cholesterol was significantly higher in Hargeisa than in Oslo in both genders (Table 3). The prevalence of diabetes 
among men tended to be higher in Hargeisa compared to Oslo, but the differences were not significant (Table 3).

Table 3. Prevalence (\%) of risk factors among men and women from Oslo and Hargeisa, age adjusted ${ }^{\mathrm{a}}$.

\begin{tabular}{|c|c|c|c|}
\hline \multirow{2}{*}{ Risk Factors } & \multicolumn{3}{|c|}{ Prevalence, $\%(95 \% \mathrm{CI})$} \\
\hline & Oslo & Hargeisa & $p$ Value \\
\hline \multicolumn{4}{|l|}{ Men } \\
\hline Overweight/obese $\left(\mathrm{BMI} \geq 25 \mathrm{~kg} / \mathrm{m}^{2}\right)$ & $61.5(52.0,71.1)$ & $22.9(15.7,30.0)$ & $<0.001$ \\
\hline Hypertension (SBP $\geq 140 \mathrm{mmHg}$ or $\mathrm{DBP} \geq 90 \mathrm{mmHg}$ and/or medicated) & $34.1(24.6,43.5)$ & $32.9(24.5,41.3)$ & 0.860 \\
\hline Diabetes (FSG $\geq 7.0 \mathrm{mmol} / \mathrm{l}$ and/or medicated) & $5.4(6.8,10.2)$ & $8.3(4.3,16.6)$ & 0.467 \\
\hline High cholesterol (TC/HDL ratio $\geq 5$ and/or medicated) & $19.1(10.2,28.0)$ & $35.0(22.6,47.4)$ & 0.040 \\
\hline Current smokers & $20.1(12.4,27.9)$ & $27.1(19.8,34.4)$ & 0.209 \\
\hline Alcohol consumption & $8.6(3.2,14.1)$ & 0 & $\mathrm{n} / \mathrm{a}$ \\
\hline \multicolumn{4}{|l|}{ Women } \\
\hline Overweight/obese $\left(\mathrm{BMI} \geq 25 \mathrm{~kg} / \mathrm{m}^{2}\right)$ & $78.1(70.4,85.9)$ & $64.3(61.1,67.5)$ & 0.005 \\
\hline Hypertension (SBP $\geq 140 \mathrm{mmHg}$ or $\mathrm{DBP} \geq 90 \mathrm{mmHg}$ and/or medicated) & $17.4(9.9,25.0)$ & $34.9(31.5,38.4)$ & 0.001 \\
\hline Diabetes (FSG $\geq 7.0 \mathrm{mmol} / \mathrm{l}$ and/or medicated) & $9.4(3.1,15.7)$ & $11.1(8.3,13.9)$ & 0.649 \\
\hline High cholesterol (TC/HDL ratio $\geq 5$ and/or medicated) & $6.0(1.0,11.1)$ & $21.0(17.4,24.6)$ & 0.003 \\
\hline Current smokers & 0 & 0 & \\
\hline Alcohol consumption & 0 & 0 & \\
\hline
\end{tabular}

Overweight/obesity prevalence was significantly higher among men in Oslo than in Hargeisa and was similarly higher among women in Oslo than in Hargeisa (Table 3). No women or men in Hargeisa reported any alcohol consumption, although 9\% of men in Oslo did. No women in either location reported currently smoking, while the smoking prevalence was $27 \%$ among men in Hargeisa and 20\% among men in Oslo (Table 3).

In an additional analysis, we found that $97.8 \%$ of Somalis in Hargeisa used palm oil for food preparation such as cooking, frying, and baking. In contrast, $76.6 \%$ of Somalis in Oslo used either olive, rapeseed, or sunflower oil in food preparation.

We also compared BMI, SBP, and DBP in those who provided a blood sample and those who did not. However, BMI, SBP, and DBP did not differ significantly between these two groups. The only exception was that BMI was significantly different in men in Oslo (data not shown).

\section{Predicted Framingham Risk Score}

The mean predicted Framingham risk scores increased substantially with age (Figures 1 and 2). The mean predicted risk was not significantly different in men from Hargeisa and Oslo $(p=0.98$ for the lipid-based score and $p=0.70$ for the BMI-based score). Similar results were found among women ( $p=0.61$ for the lipid-based score and $p=0.83$ for the BMI-based score). However, compared to women, men had significantly higher risk scores $(p<0.001$ the lipid-based score and $p<0.001$ for the BMI-based score). The estimated proportions with a predicted CVD risk of $\geq 10 \%$ were not significantly different between the two locations, although it tended to be higher in men from Hargeisa (Table 4). Additionally, there was no significant relationship between the lipid-and BMI-based Framingham risk scores and educational level in men and women (Table 5). We ran the same analysis specified by location, which was not significant (data not shown). 
Table 4. Predicted 10 -year cardiovascular disease (CVD) risk of $\geq 10 \%$ using the Framingham risk scores based on lipids and BMI, age adjusted.

\begin{tabular}{|c|c|c|c|c|c|c|}
\hline \multirow{2}{*}{$\begin{array}{c}\text { Predicted Risk } \\
\text { Lipid-based }\end{array}$} & \multicolumn{3}{|c|}{ Men } & \multicolumn{3}{|c|}{ Women } \\
\hline & $\begin{array}{c}\text { Oslo } \\
(n=73)\end{array}$ & $\begin{array}{l}\text { Hargeisa } \\
(n=50)\end{array}$ & $p$ Value & $\begin{array}{c}\text { Oslo } \\
(n=82)\end{array}$ & $\begin{array}{l}\text { Hargeisa } \\
(n=470)\end{array}$ & $p$ Value \\
\hline $\begin{array}{c}\text { Predicted } 10 \text {-year risk } \geq 10 \% \\
\%(95 \% \mathrm{CI}), \text { at age } 45 \text { years }\end{array}$ & $\begin{array}{c}22.8 \\
(8.8,36.8)\end{array}$ & $\begin{array}{l}49.6 \\
(11.5 \\
87.7) \\
\end{array}$ & 0.118 & $\begin{array}{c}8.5 \\
(1.3,15.6)\end{array}$ & $\begin{array}{c}8.4 \\
(4.5,12.5)\end{array}$ & 0.987 \\
\hline BMI-based & $\begin{array}{c}\text { Oslo } \\
(n=101)\end{array}$ & $\begin{array}{l}\text { Hargeisa } \\
(n=134)\end{array}$ & $p$ Value & $\begin{array}{c}\text { Oslo } \\
(n=103)\end{array}$ & $\begin{array}{l}\text { Hargeisa } \\
(n=860)\end{array}$ & $p$ Value \\
\hline $\begin{array}{l}\text { Predicted } 10 \text {-year risk } \geq 10 \%, \\
\%(95 \% \mathrm{CI}), \text { at age } 45 \text { years }\end{array}$ & $\begin{array}{l}41.4 \\
(27.0 \\
55.7)\end{array}$ & $\begin{array}{l}54.4 \\
(33.1 \\
75.8)\end{array}$ & 0.335 & $\begin{array}{c}9.1 \\
(0.1,16.3)\end{array}$ & $\begin{array}{c}8.6 \\
(5.9,11.3)\end{array}$ & 0.895 \\
\hline
\end{tabular}

Table 5. Estimated Framingham risk score by education, age adjusted ${ }^{\mathrm{a}}$.

\begin{tabular}{|c|c|c|c|c|c|c|}
\hline \multirow{2}{*}{$\begin{array}{c}\text { Level of Education } \\
\text { Men }\end{array}$} & \multicolumn{3}{|c|}{ Lipid-Based Framingham Risk Score } & \multicolumn{3}{|c|}{ BMI-Based Framingham Risk Score } \\
\hline & $N=123$ & Mean (95\% CI) & $p$ Value & $N=235$ & Mean (95\% CI) & $p$ Value \\
\hline \multicolumn{7}{|l|}{ Education } \\
\hline$<$ Secondary school & 35 & $5.5(3.0,7.9)$ & \multirow{2}{*}{0.890} & 73 & $5.8(4.3,7.4)$ & \multirow{2}{*}{0.149} \\
\hline$\geq$ Secondary school & 88 & $5.3(3.0,7.4)$ & & 162 & $7.2(5.6,8.8)$ & \\
\hline Women & $N=552$ & Mean $(95 \% \mathrm{CI})$ & $p$ Value & $N=963$ & Mean $(95 \% \mathrm{CI})$ & $p$ Value \\
\hline \multicolumn{7}{|l|}{ Education } \\
\hline$<$ Secondary school & 445 & $3.6(3.0,4.3)$ & \multirow{2}{*}{0.078} & 781 & $3.7(3.2,4.2)$ & \multirow{2}{*}{0.897} \\
\hline$\geq$ Secondary school & 107 & $3.1(2.3,3.9)$ & & 182 & $3.8(3.0,4.5)$ & \\
\hline
\end{tabular}

\section{Discussion}

In spite of a higher mean BMI and a higher prevalence of overweight and/or obesity among participants in Oslo, there was no apparent difference in the predicted Framingham risk scores in our study populations. However, blood pressure was significantly higher among women in Hargeisa compared to women in Oslo, and in both genders, blood lipids tended to be more favorable in Oslo than in Hargeisa. To our knowledge, this is the first article to assess CVD risk factors and to estimate the predicted risk of CVD among Somalis living in Norway and in Somaliland.

Framingham risk scoring predicts the absolute risk of future CVD and is used to inform the clinical management of asymptomatic individuals. It also provides valuable insight into the cumulative effect of the included risk factors on future CVD occurrence in our study populations. Based on our results, men had a higher Framingham risk scores than women. This is in line with previous research and has been reported in other populations of African origin across the socio-economic spectrum and among immigrant groups in Norway $[11,20]$. The similar Framingham risk levels in Oslo and Hargeisa suggest that the sums of negative and positive factors are rather similar in the two locations.

There were differences in cardiovascular risk factors between the two locations and genders. Blood lipids were more favorable in Oslo than in Hargeisa. Men and women in Hargeisa had lower HDL cholesterol and a higher ratio of total cholesterol to HDL cholesterol when compared to men and women in Oslo. Mean triglyceride levels were also higher in Hargeisa than in Oslo, whereas the mean TC levels were not different between Oslo and Hargeisa. This is in accordance with previous results from a comparative study on Sri Lankans in Norway and Sri Lanka [31], where Sri Lankans in Oslo, 
despite their higher BMI, had a more favorable lipid profile when compared with their counterparts in Sri Lanka, possibly due to healthier nutritional practices and oil used after migration [32].

In our study, we found that Somalis in Oslo used healthier oil in food preparation than Somalis in Hargeisa, indicating that the type of fat used may play a role in the more favorable lipid profile in Oslo, as the type of fat (saturated versus unsaturated) affects blood lipid concentration and CVD risk [33]. Although we did not collect information on family income in any of the settings, the expectation is that those living in Oslo might have a higher income that can improve their access to a healthy diet and to foods with better nutritional value than those living in Hargeisa. Moreover, blood pressure was higher in women living in Hargeisa compared to Oslo, whereas similar differences were not evident in men. Comparing our findings with results from the Oslo immigrant study, the systolic blood pressure in Somali men in Oslo was rather similar to those of the other immigrant men. However, the Somali women in our study were in the lower range of systolic blood pressure when compared to women from Pakistan, Sri Lanka, and Turkey [12].

Smoking was non-existent in women, and in men, the prevalence estimate was higher in Hargeisa compared to Oslo, although this was not statistically significant. This contributes to the lower Framingham scores in women than in men as smoking is an important variable in the Framingham risk model as well as in lived cardiovascular health, and it is evidently a dire public health threat affecting the men in this population [34].

Despite the higher BMI among the Oslo participants, men and women from Hargeisa in this study tended to have a higher prevalence of diabetes, although the differences were not significant. In general, other studies have reported a strong relationship between BMI and increased risk of metabolic diseases such as diabetes mellitus [35,36]. While we do not fully understand this pattern, an explanation might be that there are additional environmental factors which increase the risk of developing metabolic conditions in Hargeisa, such as different nutrition opportunities and different access to health care.

No relationship was found between the mean scores of Framingham risk and educational level among the genders, which is contrary to the results of other studies [37,38]. Further research on the relationship between CVD and social determinants of health among Somalis in Hargeisa and Oslo, as part of the diaspora from Somaliland, would provide additional beneficial insight into this phenomenon.

\section{Strengths and Limitations}

This study has several strengths. The study contributes to the limited body of research on cardiovascular risk factors among Somalis who live in the Horn of Africa and Somalis who live as part of the diaspora in Norway. Both studies used a similar design, the same standardized questionnaires, protocols, equipment, and the same laboratory for blood sample analysis in Oslo, Norway, which facilitated comparison between the two studies. As this paper included major CVD risk factors and predicted the combined effect of risk factors using the Framingham risk scores, these results might be of interest both to public health and in clinical settings.

However, we recognize a number of limitations when interpreting these results. In the Hargeisa study, there is under-representation and possible selection bias among the men. In our study, we used the Kish grid, as the Kish grid addresses the selection of gender and age in a sample, but there is discussion as to whether the Kish grid can provide a representative sample for gender [39]. During the study, more women than men were in households. Moreover, 50 eligible men refused or were not available after several attempts at contact. If the selected person was not at home, we left a note that our team would come back the next day, and if they were not present after a second attempt, we selected the next eligible person from the Kish grid. According to Somali culture, women are often at home during the daytime while men are away working or socializing with other men. Therefore, there might have been a selection bias among men who were home and included in the study, as they may have been home and willing to participate for special reasons such as poor health or lack of work. Again, results pertaining to the low number of men in this study should be treated cautiously. 
There is also a possibility that the Oslo study suffered some selection bias. We attempted to recruit all eligible individuals, and those who did participate may have had personal motivations for doing so. On the other hand, the proportion of those who participated is unclear as the living addresses of immigrants are often not up to date in the Norwegian Population Registry. Nevertheless, previous analysis of self-selection bias in studies of immigrants in Oslo suggests that it does not influence prevalence estimates to any great degree [40], although that study did not focus on Somalis.

The low number of participants who participated in the blood sample analysis is a possible limitation of this study. Although this was offered to all participants, ultimately, $72 \%$ of those in Oslo and $54 \%$ of those in Hargeisa took part. This might have been due to negative perceptions towards blood sampling in Somali culture or the location of the blood collection service station and may limit the interpretations that can be made from results using the blood sample analysis. Nevertheless, BMI and systolic and diastolic blood pressure did not differ significantly between participants attending and not attending blood sample drawing, with the exception that BMI was significantly different among men in Oslo.

\section{Conclusions}

In spite of the high BMI in Oslo, the study demonstrated that most CVD risk factors among women from Hargeisa were higher when compared to those among Somali women living in Oslo, with somewhat similar differences seen in men. However, the overall predicted CVD risk was not significantly different between the two locations. In addition, as overweight/obesity, smoking, hypertension, and high cholesterol were observed at concerning prevalence levels, intervention efforts are necessary and should be supported by continuing to monitor CVD risk factors in both populations.

Author Contributions: A.A.M., H.E.M. and M.K.R.K. planned the study. S.H.A. and A.A.M. carried out the data collection in Hargeisa and Oslo, respectively. H.S., S.H.A. and N.M. performed data analysis. S.H.A. and N.M. drafted the manuscript. H.E.M., M.K.R.K., E.B., A.S.H., A.A.M. critically revised the manuscript and contributed to the interpretation of the findings. All authors approved the final version of the manuscript.

Funding: Norwegian Health Directorate and the University of Oslo (UiO) funded the study.

Acknowledgments: The authors are grateful to all study participants, the Somali organization, and Sagene Life Health Centre for their help with this study. The authors also thank Deria Ereg, College of Medicine and Health Sciences for facilitating and supporting the study in Hargeisa, Somaliland.

Conflicts of Interest: The authors confirm that the content of this article is subject to no conflicts of interest.

\section{Abbreviations}

CVD: cardiovascular disease; BMI: body mass index; DBP: diastolic blood paressure, SBP: systolic blood pressure, SSA: sub-Saharan Africa; HDL: high-density lipoprotein; LDL: low-density lipoprotein; MI: myocardial infarction; TC: total cholesterol; TG: triglycerides.

\section{References}

1. Dalal, S.; Beunza, J.J.; Volmink, J.; Adebamowo, C.; Bajunirwe, F.; Njelekela, M.; Mozaffarian, D.; Fawzi, W.; Willett, W.; Adami, H.O.; et al. Non-communicable diseases in sub-Saharan Africa: What we know now. Int. J. Epidemiol. 2011, 40, 885-901. [CrossRef] [PubMed]

2. Ziraba, A.K.; Fotso, J.C.; Ochako, R. Overweight and obesity in urban Africa: A problem of the rich or the poor? BMC Public Health 2009, 9, 465. [CrossRef] [PubMed]

3. Keates, A.K.; Mocumbi, A.O.; Mpiko, N.; Karen, S.; Simon, S. Cardiovascular disease in Africa: Epidemiological profile and challenges. Nat. Rev. Cardiol. 2017, 14, 273-293. [CrossRef] [PubMed]

4. Global Atlas on Cardiovascular Disease Prevention and Control. 2011. Available online: https://www.who. int/cardiovasculardiseases/publications/atlas_cvd/en/ (accessed on 26 May 2019).

5. Scott, A.; Ejikeme, C.S.; Clottey, E.N.; Thomas, J.G. Obesity in sub-Saharan Africa: Development of an Ecological Theoretical Framework. Health Promot. Int. 2013, 28, 4-16. [CrossRef] [PubMed]

6. Unrepresented Nations \& People's Organization (UNPO). Member Profile: Somaliland in UNPO. Brussels, Belgium 2017. Available online: http://unpo.org/downloads/2343.pdf (accessed on 28 September 2018). 
7. World Health Organization. Global Status Report on Noncommunicable Diseases 2014; World Health Organization: Geneva, Switzerland, 2014.

8. Somalia's Missing Million; The Somali Diaspora and Its Role in Development 2009. Available online: http: //www.so.undp.org/content/somalia/en/home/library/poverty/publication3.html (accessed on 26 May 2019).

9. Table: 09817: Immigrants and Norwegian-Born to Immigrant Parents, by Immigration Category, Country Background and Percentages of the Population. Available online: https://www.ssb.no/en/statbank/table/09817/ (accessed on 28 June 2019).

10. Public Health Challenges of Immigrants in Norway: A Research Review. Available online: https://www.fhi.no/globalassets/dokumenterfiler/rapporter/2010/public-health-challenges-of-immigrantsin-norway-nakmireport-2-2010.pdf (accessed on 28 June 2019).

11. Kumar, B.N.; Selmer, R.; Lindman, A.S.; Tverdal, A.; Falster, K.; Meyer, H.E. Ethnic differences in SCORE cardiovascular risk in Oslo, Norway. Eur. J. Cardiovasc. Prev. Rehabil. 2009, 16, 229-234. [CrossRef]

12. Glenday, K.; Kumar, B.N.; Tverdal, A.; Meyer, H.E. Cardiovascular disease risk factors among five major ethnic groups in Oslo, Norway: The Oslo Immigrant Health Study. Eur. J. Cardiovasc. Prev. Rehabil. 2006, 13, 348-355. [CrossRef]

13. Rabanal, K.S.; Selmer, R.M.; Igland, J.; Tell, G.S.; Meyer, H.E. Ethnic inequalities in acute myocardial infarction and stroke rates in Norway 1994-2009: A nationwide cohort study (CVDNOR). BMC Public Health 2015, 15, 1073. [CrossRef] [PubMed]

14. D'Agostino, R.B.; Grundy, S.; Sullivan, L.M.; Wilson, P.; the CHD Risk Prediction Group. Validation of the framingham coronary heart disease prediction scores: Results of a multiple ethnic groups investigation. JAMA 2001, 286, 180-187. [CrossRef]

15. D’Agostino, R.B.; Vasan, R.S.; Pencina, M.J.; Wolf, P.A.; Cobain, M.; Massaro, J.M.; Kannel, W.B. General Cardiovascular Risk Profile for Use in Primary Care. J. Am. Heart Assoc. 2008, 117, 743-753. [CrossRef]

16. Eichler, K.; Puhan, M.A.; Steurer, J.; Bachmann, L.M. Prediction of first coronary events with the Framingham score: A systematic review. Am. Heart J. 2007, 153, 722-731. [CrossRef]

17. Schofield, P.; Chen, R.; Crichton, N. Methods for assessing cardiovascular disease risk in a UK black population. Heart 2012, 98, 1373-1377. [CrossRef]

18. Brindle, P.M.; McConnachie, A.; Upton, M.N.; Hart, C.L.; Smith, G.D.; Watt, G.C. The accuracy of the Framingham risk-score in different socioeconomic groups: A prospective study. Br. J. Gen. Pract. 2005, 55, 838-845. [PubMed]

19. Hurley, L.P.; Dickinson, L.M.; Estacio, R.O.; Steiner, J.F.; Havranek, E.P. Prediction of cardiovascular death in racial/ethnic minorities using Framingham risk factors. Circ. Cardiovasc. Qual. Outcomes 2010, 3, 181-187. [CrossRef] [PubMed]

20. Dugas, L.R.; Forrester, T.E.; Plange-Rhule, J.; Bovet, P.; Lambert, E.V.; Durazo-Arvizu, R.A.; Cao, G.; Cooper, R.S.; Khatib, R.; Tonino, L.; et al. Cardiovascular risk status of Afro-origin populations across the spectrum of economic development: Findings from the Modeling the Epidemiologic Transition Study. BMC Public Health 2017, 17, 438. [CrossRef]

21. World Health Organization (WHO). Global Action Plan for the Prevention and Control of Noncommunicable Diseases 2013-2020; World Health Organization: Geneva, Switzerland, 2013.

22. Ahmed, S.H.; Meyer, H.E.; Kjøllesdal, M.K.; Madar, A.A. Prevalence and Predictors of Overweight and Obesity among Somalis in Norway and Somaliland: A Comparative Study. J. Obes. 2018. [CrossRef]

23. Ahmed, H.A. Prevalence of Cardiovascular Disease Risk Factors in Urban Garissa Residents; University of Nairobi: Nairobi, Kenya, 2012.

24. Kish, L. A Procedure for Objective Respondent Selection within the Household. J. Am. Stat. Assoc. 1949, 44, 380-387. [CrossRef]

25. World Health Organization (WHO). STEPS: A Framework for Surveillance, in the WHO STEPwise Approach to Surveillance of Noncommunicable Diseases (STEPS); World Health Organization: Geneva, Switzerland, 2003.

26. Takahashi, H.; Yoshika, M.; Yokoi, T. Validation of Omron RS8, RS6, and RS3 Home Blood Pressure Monitoring Devices, in Accordance with the European Society of Hypertension International Protocol Revision 2010. Vasc. Health Risk Manag. 2013, 9, 265-272. [CrossRef]

27. World Health Organization (WHO). Waist Circumference and Waist-Hip Ratio: Report of A WHO Expert Consultation; World Health Organization: Geneva, Switzerland, 2011; p. 39. 
28. World Health Organization. Definition and Diagnosis of Diabetes Mellitus and Intermediate Hyperglycemia: Report of a WHO/IDF Consultation; World Health Organization: Geneva, Switzerland, 2006.

29. Hjerte-/Karsykdom Risikofaktorer Tolkning Fürst Medisinsk Laboratorium. Available online: http://www. furst.no/analyse-og-klinikk/kliniske-problemstillinger/hjerte-karsykdom-risikofaktorer/tolkning/ (accessed on 1 August 2018).

30. Framingham Heart Study Primary Risk Functions. Available online: https://www.framinghamheartstudy. org/fhs-risk-functions/cardiovascular-disease-10-year-risk/ (accessed on 26 May 2019).

31. Tennakoon, S.U.B.; Kumar, B.N.; Nugegoda, D.B.; Meyer, H.E. Comparison of cardiovascular risk factors between Sri Lankans living in Kandy and Oslo. BMC Public Health 2010, 10, 654. [CrossRef]

32. Tennakoon, S.U.; Kumar, B.N.; Meyer, H.E. Differences in selected lifestyle risk factors for cardiovascular disease between Sri Lankans in Oslo, Norway, and in Kandy, Sri Lanka. Asia Pac. J. Public Health 2015, 27, 616-625. [CrossRef]

33. Mensink, R.P.; Katan, M.B. Effect of dietary fatty acids on serum lipids and lipoproteins. A meta-analysis of 27 trials. Arterioscler. Thromb. 1992, 12, 911-919. [CrossRef]

34. Hajar, R. Framingham Contribution to Cardiovascular Disease. Heart Views 2016, 17, 78-81. [CrossRef] [PubMed]

35. Gele, A.A.; Pettersen, K.S.; Kumar, B.; Torheim, L.E. Diabetes Risk by Length of Residence among Somali Women in Oslo Area. J. Diabetes Res. 2016. [CrossRef] [PubMed]

36. Bays, H.E.; Chapman, R.H.; Grandy, S.; the SHIELD Investigators' Group. The relationship of body mass index to diabetes mellitus, hypertension and dyslipidaemia: Comparison of data from two national surveys. Int. J. Clin. Pract. 2007, 61, 737-747. [CrossRef] [PubMed]

37. Cappuccio, F.P.; Miller, M.A. Cardiovascular disease and hypertension in sub-Saharan Africa: Burden, risk and interventions. Intern. Emerg. Med. 2016, 11, 299-305. [CrossRef]

38. Tennakoon, S.U.; Kumar, B.N.; Selmer, R.; Mikram, M.J.; Meye, H.E. Differences in predicted cardiovascular risk in Sinhalese and Tamils in Sri Lanka compared with Sri Lankans in Norway. Asia Pac. J. Public Health 2013, 25, 452-462. [CrossRef]

39. Respondent Selection within the Household-A Modification of the Kish Grid. Available online: https: //www.stat.aau.at/Tagungen/Ossiach/Nemeth.pdf (accessed on 28 June 2019).

40. Sogaard, A.J.; Selmer, R.; Bjertness, E.; Thelle, D. The Oslo Health Study: The impact of self-selection in a large, population-based survey. Int. J. Equity Health 2004, 3, 3. [CrossRef] 